\title{
Is Teamwork Effective in the Work Place? An Analysis of Team Work Environment in the Banking Sector, Sultanate of Oman
}

\author{
Renjith Kumar R. ${ }^{1} \&$ Rajani James ${ }^{1}$ \\ ${ }^{1}$ Department of Business Studies, Nizwa College of Technology, Sultanate of Oman \\ Correspondence: Renjith Kumar R., Department of Business Studies, Nizwa College of Technology, Sultanate of \\ Oman. Tel: 968-9570-1571. E-mail: cvrrkachu@gmail.com
}

Received: January 4, 2015

Accepted: February 5, 2015

Online Published: February 25, 2015

doi:10.5539/ibr.v8n3p173

URL: http://dx.doi.org/10.5539/ibr.v8n3p173

\begin{abstract}
This study aims at analysing team environmental factors that influence the employees in the banking sector in Nizwa. The objective is to analyse the influence of team work attributes on gender, experience and education. Bernhard A Zimmermann's model of team attributes is adopted for this study. A sample of 89 employees is taken for the study from 13 banks in Nizwa, Sultanate of Oman. The analysis revealed males contribute more and perform better than females in the banking sector. Employees who are less experienced have high level of trust, good in managing conflicts and are more result oriented than experienced employees. Trust, conflict management and result orientation are the high level attributes among team work variables in the banking sector. It is also proved that the less educated employees show more levels of trust, conflict management, commitment, accountability and focus on results than highly educated employees.
\end{abstract}

Keywords: trust, conflict management, commitment, accountability, result orientation

\section{Introduction}

Today's highly complex organizations put a heavy emphasis on effective team work. Yet most teams are far from working at their best. In addition, a more complex global organisational framework puts an extra dimension and challenge to this phenomenon. Employees in an organization work together as a group and they develop a culture, team and working environment. Team climate refers to the recurring patterns of behavior, attitudes and feelings that characterize life in the organization. A congenial team environment reduces errors, stress, improves working environment, consistency and openness in communication, thereby creating a team climate. Organizations thus contribute more creative ideas and solutions, respect and recognize others, listen and share information, and participate fully for the fulfillment of vision and objectives of the organisation. A proper understanding of team work will help the employees to perform better to work as a group. This will enhance the efficiency and productivity of the firm. The purpose of this study is to examine the variables that contribute for team climate. Also this study paves way for creating awareness about team work variables thus improving the team work culture. The strength of this study is that it addresses the team climate variables based on gender, experience and occupation. Few studies have been conducted adopting Bernhard A Zimmermann's model and the result of this study will contribute more to the existing body of literature.

\section{Literature Review}

Team climate for innovation is a combining site of innovation research and team research. A correlative research shows that Team Climate Inventory has good internal consistency and reliability in China. Significant positive relationships were found between Team Climate Inventory scales and the team innovativeness (Yuan et al., 2008). Team climate is an important factor in the pursuit of team effectiveness. Participants had positive team experiences and improved their team skills among other effects (Anderson \& West, 1994). A study on three-dimensional organizational commitment affective, normative, and continuance commitment were investigated by multiple regression analyses. Continuance and normative commitment were both explained by job characteristics, i.e., by the perception of the job as interesting, affective commitment could not be explained with the set of variables. It is affective commitment which particularly accounts for variance in search intentions as well as in turnover intentions (Gautam et al., 2001). A study by Dick et al identified the structure of organizational citizenship behavior and its relation to organizational commitment in Nepal. Exploratory and confirmatory factor analyses revealed two factors of organisational citizenship behaviour, altruism and 
compliance. Structural equation analysis showed a positive relation between affective and normative commitment on the one hand and both citizenship factors on the other. Continuance commitment was negatively related to compliance and unrelated to altruism (Dick et al., 2005). A study on Team Climate Inventory analyzed the four-factor theory underlying factor structure, internal homogeneity; predictive validity and factor replicability across groups of the summarized measure are presented. It demonstrates robust psychometric properties, with acceptable levels of reliability and validity (Anderson \& West, 1998). Another study examined the factor structure and psychometric properties of the 38-item Team Climate Inventory and the 14-item short version using a sample of 72 four-person teams of management undergraduates in a Canadian university. The Team Climate Inventory shows promise as a multidimensional measure of the team climate construct in both student and employee teams (Robert \& Pamela, 2002). Team climate relates to the manner of working together that the team has developed, and accordingly, it can include several different aspects, such as communication patterns, participation, safety, norms, cohesiveness, task style, vision, and innovativeness (Anderson \& West, 1994). Anderson and West $(1994,1998)$ have worked extensively on climate within teams and have developed a scale to measure team climate. According to their studies, climate within the team can be measured using four dimensions, namely, vision, participatory safety, support for innovation, and task orientation.

\section{Scope of the Study}

This study helps to promote a better teamwork environment in the banking sector in Nizwa, Sultanate of Oman. The study evaluates the current team work environment of thirteen banks in Nizwa by adopting Bernhard A Zimmermann's model. It creates awareness for the banks and its employees to improve their team performance. Besides, the study aims at examining the employees' involvement in team work effectiveness. Till date, no empirical studies have been conducted in banking sector specifically in Nizwa and hence the outcome of this research has many implications for banks and its employees for enhancing teamwork atmosphere in the organisation. Hence this research is significant and relevant.

\section{Objectives of the Study}

1) To analyse the variables that affect teamwork in the banking sector in Nizwa.

2) To identify whether team work in banks is influenced by gender.

3) To determine if teamwork is affected by experience of the employees.

4) To evaluate whether there is a relation between education and team work.

\section{Research Methodology}

The data for the research is collected from 13 banks in Nizwa, Sultanate of Oman namely Bank Muscat, National Bank of Abu Dhabi, Sohar Islamic bank, HSBC, Bank Nizwa, Ahli Bank, Oman Arab Bank, National Bank of Oman, Alizz Islamic Bank, Qatar International Bank, Bank Sohar, Bank Dhofar, Habib Bank. Primary data is collected by using a structured questionnaire method which is distributed to all the bank employees. The response rate is $94 \%$. Thus a sample of 89 employees is collected from these banks. The statements in the instrument are adopted from Bernhard A. Zimmerman's model consisting of the five variables, namely trust, conflict management, commitment, accountability and result orientation. A five point scale is used for rating the statements from strongly agree to strongly disagree. Hypothesis is tested by using Chi square and the level of each variable is categorized as low, medium and high by using the formula: Average +-S.D. ANOVA is used to identify the equality of means among the team climate variables. The duration of the research study is from May 2014 to December 2014.

\section{Results and Discussion}

\subsection{Trust}

A well-developed level of trust in a team enables the team to work openly with one another. If the level of trust is medium or reasonable the organization should plan activities to develop trust in the team. The average trust score is 4.28 and the standard deviation calculated is 0.48 . The levels of trust of employees are shown in Table 1. From the sample respondents, $68 \%$ have medium level of trust and $21 \%$ of the employees have high level of trust.

Table 1. Level of trust

\begin{tabular}{lcccc}
\hline Level of Trust & Low & Medium & High & Total \\
\hline Number of responses & $10(11)$ & $60(68)$ & $19(21)$ & 89 \\
\hline
\end{tabular}


The relation between gender and level of trust is as follows. The average score of trust for males and females is 4.28 which is the same as the average (4.28). Table 2 shows the level of trust among the bank employees.

Table 2. Gender and trust

\begin{tabular}{lcccc}
\hline \multicolumn{1}{c}{ Trust } & Low & Medium & High & Total \\
Gender & & & & \\
\hline Males & $7(15)$ & $30(62)$ & $11(23)$ & 48 \\
Females & $3(7)$ & $30(73)$ & $8(20)$ & 41 \\
Total & $10(11)$ & $60(68)$ & $19(21)$ & 89 \\
\hline
\end{tabular}

From Table 2, it is observed that $23 \%$ of the male employees have high level of trust which is greater than the overall percentage (21\%). The level of trust for female employees is $20 \%$ which is less than the overall percentage. Ho: Male employees have a higher level of trust than female employees. The calculated value of $\chi^{2}(1.53)$ is lower than the critical value (5.99) at 5\% confidence level with 2 degrees of freedom. It is thus concluded that males show more trust level than females in the work environment.

The relationship between experience and trust is discussed in Table 3 . The average value of trust for employees with less than 2 years and more than 6 years of experience are 4.32 and 4.36 respectively each one being more than the average trust (4.28) whereas the average level of trust for employees with experience between 2 to 4 years and 4 to 6 years is 4.19 which is less than the average (4.28). To verify if there is any difference between the experience and trust level of employees, Table 3 is prepared.

Table 3. Experience and trust

\begin{tabular}{|c|c|c|c|c|}
\hline $\begin{array}{ll}\text { Experience } & \text { Trust } \\
\end{array}$ & Low & Medium & High & Tota \\
\hline$<2$ years & $2(13)$ & $8(50)$ & $6(37)$ & 16 \\
\hline 2 to 4 years & $2(12)$ & $12(76)$ & $2(12)$ & 16 \\
\hline 4 to 6 years & $4(20)$ & $12(60)$ & $4(20)$ & 20 \\
\hline$>6$ years & $2(5)$ & $28(76)$ & 7 (19) & 37 \\
\hline Total & $10(11)$ & $60(68)$ & $19(21)$ & 89 \\
\hline
\end{tabular}

Table 3 exhibits $76 \%$ of employees who are experienced 2 to 4 years and more than 6 years have a medium level of trust which is more than the overall percentage (68\%). The trust level is high for $37 \%$ of employees experienced less than 2 years which is more than the overall percentage (21\%). $20 \%$ of employees who have experience of 4 to 6 years have low trust level which is more than overall percentage of $11 \%$. Hence the following hypothesis is framed and tested. Ho: Employees who are less experienced have a high level of trust than experienced employees. The calculated value of $\chi^{2}(6.58)$ is lower than the critical value (12.59) at 5\% confidence level with 6 degrees of freedom. The null hypothesis is accepted and it is proved that employees who are less experienced have a high level of trust than experienced employees.

The relationship between education and trust is addressed through Table 4. The average score of trust for employees with baccalaureate degree and higher secondary education is 4.12 and 4.16 which is less than the overall average (4.28). The average value of trust for employees having higher diploma is 4.28 which is the same as the overall average. The average trust for employees with diploma is 4.34 which is higher than the overall average. Table 4 checks if there is any relationship between the education and trust level of employees.

Table 4. Education and trust

\begin{tabular}{lcccc}
\hline Education & Low & Medium & High & Total \\
\hline Higher Secondary & $2(25)$ & $3(37)$ & $3(38)$ & 8 \\
Diploma & $3(6)$ & $36(74)$ & $10(20)$ & 49 \\
Higher Diploma & $3(14)$ & $14(63)$ & $5(23)$ & 22 \\
Baccalaureate & $2(20)$ & $7(70)$ & $1(10)$ & 10 \\
Total & $10(11)$ & $60(68)$ & $19(21)$ & 89 \\
\hline
\end{tabular}


The Table 4 displays 38\% employees who completed their higher secondary education have a high level of trust which is more than the overall percentage of $21 \% .74 \%$ of the employees who completed diploma have medium level of trust which is more than the overall percentage of 68\%. Ho: Employees with higher secondary education show high level of trust. The calculated value of $\chi^{2}(6.29)$ is less than the critical value (12.59) at 5\% confidence level with 6 degrees of freedom. Thus it is proved that less qualified employees exhibit high trust level than the highly qualified employees.

\subsection{Conflict Management}

A well-developed level of conflict management enables the team to handle conflicts, and stimulates greater team creativity. This ability is used to develop ideas. If the conflict management is medium, an organization should plan some interventions to develop the team's ability to handle conflicts well. A low level of conflict management reveals that either there are no conflicts or there are constant fights with each other with no resolution. There is a need of some external support to develop team's ability to handle conflicts constructively. The average score of conflict management is 4.22 and the standard deviation calculated is 0.51 . Thus the level of conflict management is as follows.

Table 5. Levels of conflict management

\begin{tabular}{lcccc}
\hline Conflict Management & Low & Medium & High & Total \\
\hline Number of responses & $15(17)$ & $56(63)$ & $18(20)$ & 89 \\
\hline
\end{tabular}

Table 5 exhibits that out of 89 employees, $63 \%$ have medium level of conflict management. $20 \%$ of the bank employees have high level of conflict management. The relation between gender and level of conflict management is analysed in Table 6 . The average score of conflict management for males is 4.28 which is more than the average (4.22) and that for females is 4.15 which is less than the overall average. The differences in the level of conflict management between the genders are shown in Table 6.

Table 6. Gender and conflict management

\begin{tabular}{|c|c|c|c|c|}
\hline Gender $\quad$ Conflict Management & Low & Medium & High & Total \\
\hline Males & $6(12)$ & $32(67)$ & $10(21)$ & 48 \\
\hline Females & $9(22)$ & $24(58)$ & $8(20)$ & 41 \\
\hline Total & $15(17)$ & $56(63)$ & $18(20)$ & 89 \\
\hline
\end{tabular}

It is evident from the Table 6 that $21 \%$ of the male employees have high level of conflict management which is greater than the overall percentage (20\%). The level of conflict management for female employees is $20 \%$ which is the same as the overall percentage. Ho: Male employees have higher level of conflict management than female employees. The $\chi^{2}$ value (1.42) is less than the critical value (5.99) at 5\% confidence level with 2 degrees of freedom. The null hypothesis is accepted and it is thus concluded that males can manage conflicts better than females in the work environment.

The relationship between experience and conflict management is compared. The average score of conflict management for employees experienced less than 2 years and more than 6 years of experience is 4.25 and 4.30 respectively which is more than the average of (4.22) whereas the average level of conflict management for employees between 2 to 4 years and 4 to 6 years is 4.15 and 4.12 respectively which is less than the average (4.22). Table 7 analyses whether there is any relationship between the experience and conflict management level of employees.

Table 7. Experience and conflict management

\begin{tabular}{|c|c|c|c|c|}
\hline $\begin{array}{l}\text { Conflict Management } \\
\text { Experience }\end{array}$ & Low & Medium & High & Total \\
\hline$<2$ years & $4(25)$ & $6(37)$ & $6(38)$ & 16 \\
\hline 2 to 4 years & $4(25)$ & $9(56)$ & $3(19)$ & 16 \\
\hline 4 to 6 years & $4(20)$ & $14(70)$ & $2(10)$ & 20 \\
\hline$>6$ years & $3(8)$ & $27(72)$ & $7 \quad$ (20) & 37 \\
\hline Total & 15 (17) & $56(63)$ & $18(20)$ & 89 \\
\hline
\end{tabular}


The Table 7 shows that $38 \%$ of employees experienced less than 2 years have high level of conflict management which is more than the overall percentage (20\%). The conflict management level is medium for $72 \%$ employees with more than 6 years of experience which is more than the overall percentage (63\%). 25\% of employees experienced between 2 to 4 years have low conflict management level which is more than overall percentage of 17\%. Ho: A high level in managing conflicts is visible in employees having less than 2 years of experience. The $\chi^{2}$ value (9) is less than the critical value (12.59) at 5\% confidence level with 6 degrees of freedom. The null hypothesis is accepted. It is inferred that employees with less experience are good in managing conflicts than experienced employees.

The relationship between education and conflict management is analysed in Table 8 . The average score of conflict management for employees who completed their higher secondary and diploma are 4.38 and 4.26 respectively which is more than the average of (4.22) whereas the average of conflict management for employees qualified with baccalaureate and higher diploma are 4.02 and 4.16 which is less than the overall average. Table 8 is prepared to determine the relationship between education and the level of conflict management of employees.

Table 8. Education and conflict management

\begin{tabular}{lcccc}
\hline Education & Low & Medium & High & Total \\
\hline Higher Secondary & & & & \\
Diploma & $1(13)$ & $4(50)$ & $3(37)$ & 8 \\
Higher Diploma & $7(15)$ & $30(61)$ & $12(24)$ & 49 \\
Baccalaureate & $4(18)$ & $15(68)$ & $3(14)$ & 22 \\
Total & $3(30)$ & $7(70)$ & 0 & 10 \\
\hline
\end{tabular}

The Table 8 demonstrates that $37 \%$ of employees with higher secondary qualification have a high level of conflict management when compared with overall employee's percentage (20\%). $30 \%$ of employees with baccalaureate degree are low on conflict management level which is more than overall percentage of 17\%. Ho: Employees with higher secondary education show high in conflict management compared with other employees. The $\chi^{2}$ value (5.87) is less than the critical value (12.59) at 5\% confidence level with 6 degrees of freedom. Thus, it is proved that less qualified employees are good in conflict management.

\subsection{Commitment}

A high level of commitment among employees towards team working enables the team to work effectively and rely on each other's support. A medium level of commitment in a team is also acceptable. However, improvement in this level will help to manage interdependent tasks. If commitment is low, the employees are unaware of team tasks. The average commitment value of the employees is 4.13 and the standard deviation calculated is 0.52 . The level of commitment of employees is shown in Table $9.14 \%$ of the employees opined that they are highly committed to the organization. $66 \%$ of the employees have medium level of commitment.

Table 9. Levels of commitment

\begin{tabular}{lcccc}
\hline Level of commitment & Low & Medium & High & Total \\
\hline Number of responses & $18(20)$ & $59(66)$ & $12(14)$ & 89 \\
\hline
\end{tabular}

The relation between gender and level of commitment is analyzed in Table 10. The average score of commitment for males is 4.17 which is more than the average (4.13) and that for females is 4.07 which is less than the overall average.

Table 10. Gender and commitment

\begin{tabular}{|c|c|c|c|c|}
\hline Gender & Low & Medium & High & Total \\
\hline Males & $9(19)$ & $30(62)$ & $9(19)$ & 48 \\
\hline Females & $9(22)$ & $29(71)$ & $3(7)$ & 41 \\
\hline Total & $18(20)$ & $59(66)$ & $12(14)$ & 89 \\
\hline
\end{tabular}


Table 10 exhibits the differences in the level of commitment between the genders. It is found that $19 \%$ of the male employees have high level of commitment which is greater than the overall percentage (14\%). The level of commitment for female employees is $7 \%$ which is less than the overall percentage. Ho: Male employees have a higher level of commitment than female employees. The $\chi^{2}$ value (2.48) is less than the critical value (5.99) at 5\% confidence level with 2 degrees of freedom. The null hypothesis is accepted and it is concluded that male employees have high level of commitment than female employees.

The relationship between experience and commitment is discussed in Table 11. The average score of commitment for employees experienced more than 6 years of experience is 4.25 which is more than the average of (4.13) whereas the average value of commitment for employees experienced less than 2 years (4.11), 2 to 4 years (3.98) and 4 to 6 years (4.02) respectively is less than the overall average. To identify if there is any difference between the experience and commitment level of employees the Table 11 is prepared.

Table 11. Experience and commitment

\begin{tabular}{lcccc}
\hline Experience & Low & Medium & High & Total \\
\hline$<2$ years & $4(25)$ & $8(50)$ & $4(25)$ & 16 \\
2 to 4 years & $6(38)$ & $8(50)$ & $2(12)$ & 16 \\
4 to 6 years & $6(30)$ & $13(65)$ & $1(5)$ & 20 \\
$>6$ years & $2(5)$ & $30(81)$ & $5(14)$ & 37 \\
Total & $18(20)$ & $59(66)$ & $12(14)$ & 89 \\
\hline
\end{tabular}

The Table 11 displays $25 \%$ of employees experienced less than 2 years have high level of commitment which is more than the overall percentage (14\%). The commitment level is medium for $81 \%$ employees with more than 6 years of experience. $38 \%$ of employees experienced between 2 to 4 years have low commitment level which is more than the overall percentage of 20\%. Ho: Employees experienced less than 2 years shows high level of commitment. The $\chi^{2}$ value (12.66) is more than the critical value (12.59) at 5\% confidence level with 6 degrees of freedom. The null hypothesis is rejected and it is inferred that there is no relation between experience and the level of commitment.

The relationship between education and commitment is mentioned in Table 12. The average score of commitment for employees who are qualified with higher secondary (4.15), higher diploma (4.18) and diploma (4.14) are higher than the average (4.13) whereas the average commitment for employees who has baccalaureate degree is 3.92 which is less than the average. To check if there is any relationship between the education and commitment level of employees Table 12 is prepared.

Table 12. Education and commitment

\begin{tabular}{lcccc}
\hline Education & Low & Medium & High & Total \\
\hline Higher Secondary & & & & \\
Diploma & $1(12)$ & $5(63)$ & $2(25)$ & 8 \\
Higher Diploma & $11(23)$ & $32(65)$ & $6(12)$ & 49 \\
Baccalaureate & $4(18)$ & $14(64)$ & $4(18)$ & 22 \\
Total & $2(20)$ & $8(80)$ & $0(0)$ & 10 \\
\hline
\end{tabular}

Table 12 demonstrates that $25 \%$ of employees whose education level is higher secondary have a high level of commitment which is more than the overall percentage (14\%). The commitment level is medium for $65 \%$ of employees who are diploma holders which is less than the overall percentage (66\%). Ho: Employees with higher secondary education haves higher level of commitment. The $\chi^{2}$ value (3.28) is less than the critical value (12.59) at $5 \%$ confidence level with 6 degrees of freedom. The null hypothesis is accepted and is concluded that less qualified employees show high level of commitment than the experienced employees. 


\subsection{Accountability}

A high level of accountability in a team enables to work effectively and challenge each other. If the accountability is medium, organization should develop awareness for accountabilities in the team. If the accountability is low, organization should clarify the roles and responsibilities. The average score of accountability for the employees is 4.21 and the standard deviation calculated is 0.47 . Thus the level of accountability of employees is shown in Table 13. Out of 89 employees, only $66 \%$ have medium level of accountability. $14 \%$ of the employees have high level of accountability.

Table 13. Levels of accountability

\begin{tabular}{lcccc}
\hline Level of accountability & Low & Medium & High & Total \\
\hline Number of responses & $18(20)$ & $59(66)$ & $12(14)$ & 89 \\
\hline
\end{tabular}

The relation between gender and level of accountability is compared as follows. The average score of accountability for males is 4.26 which is more than the average (4.21) and that for females is 4.16 which is less than the overall average. To test whether there is any significant difference between level of accountability and the gender, Table 14 is prepared.

Table 14. Gender and accountability

\begin{tabular}{|c|c|c|c|c|}
\hline Gender & Low & Medium & High & Total \\
\hline Males & $9(19)$ & $30(62)$ & $9(19)$ & 48 \\
\hline Females & $9(22)$ & $29(71)$ & $3(7)$ & 41 \\
\hline Total & $18(20)$ & $59(66)$ & $12(14)$ & 89 \\
\hline
\end{tabular}

Table 14 shows that $19 \%$ of the male employees have high level of accountability which is greater than the overall percentage (14\%). The high level of accountability for female employees is only $7 \%$ which is less than the overall percentage. Ho: Male employees have a high level of accountability than female employees. The $\chi^{2}$ value of (2.48) is less than the critical value (5.99) at 5\% confidence level with 2 degrees of freedom. It is concluded that male employees have high level of accountability than female employees in the banking sector.

The relationship between experience and accountability is discussed in Table 15. The average score of accountability for employees who has more than 6 years and less than 2 years of experience is 4.23 and 4.26 respectively which is more than the average (4.21) whereas the average value of accountability for employees between 2 to 4 years and 4 to 6 years of experience is 4.16 and 4.19 respectively which is less than the average (4.21). To verify if there is any relationship between the experience and accountability level of employees, Table 15 is prepared.

Table 15. Experience and accountability

\begin{tabular}{|c|c|c|c|c|}
\hline Experience & Low & Medium & High & Total \\
\hline$<2$ years & $6(38)$ & $5(31)$ & $5(31)$ & 16 \\
\hline 2 to 4 years & $4(25)$ & $10(63)$ & $2(12)$ & 16 \\
\hline 4 to 6 years & $5(25)$ & $13(65)$ & $2(10)$ & 20 \\
\hline$>6$ years & $3(8)$ & $31(84)$ & $3(8)$ & 37 \\
\hline Total & $18(20)$ & $59(66)$ & $12(14)$ & 89 \\
\hline
\end{tabular}

The Table 15 displays $31 \%$ of employees with less than 2 years of experience have high level of accountability which is more than the overall percentage (14\%). The accountability level is medium for $84 \%$ for employees with more than 6 years of experience which is more than the overall percentage (66\%). Ho: Employees experienced less than 2 years exhibit high levels of accountability. The $\chi^{2}$ value (14.89) is more than the critical value (12.59) at 5\% 
confidence level with 6 degrees of freedom. Thus the null hypothesis is rejected and it is proved that there is no relationship between experience of employees and accountability.

The relationship between education and accountability is addressed. The average score of accountability for employees who completed their higher secondary and diploma is 4.52 and 4.26 respectively which is more than the average of (4.21) whereas the average accountability for employees who are qualified with baccalaureate and higher diploma are 4.15 and 3.86 which is less than the average. Table 16 exhibits the relationship between the education and the accountability level of employees.

Table 16. Education and accountability

\begin{tabular}{lcccc}
\hline Education & Low & Medium & High & Total \\
\hline Higher Secondary & $0(0)$ & $6(75)$ & $2(25)$ & 8 \\
Diploma & $9(18)$ & $32(65)$ & $8(17)$ & 49 \\
Higher Diploma & $4(18)$ & $16(73)$ & $2(9)$ & 22 \\
Baccalaureate & $5(50)$ & $5(50)$ & $0(0)$ & 10 \\
Total & $18(20)$ & $59(66)$ & $12(14)$ & 89 \\
\hline
\end{tabular}

Table 16 exhibits that $25 \%$ of employees who are educated up to higher secondary have high level of accountability which is greater than the overall percentage (14\%). The accountability level is medium for $75 \%$ whose highest qualification is higher secondary which is more than the overall percentage $(66 \%)$. $50 \%$ of employees with baccalaureate degree are low on accountability level which is more than overall percentage of $20 \%$. Ho: Less qualified employees are more accountable compared with highly qualified employees. The $\chi^{2}$ value (9.51) is less than the critical value (12.59) at 5\% confidence level with 6 degrees of freedom. Thus the null hypothesis is accepted and it is concluded that employees with less education are more accountable than more educated employees in the banking sector.

\subsection{Result Orientation}

A well-developed sense for results in a team enables the team to stay focused and deliver. If result orientation is medium, the firm should enhance performance and develop activities in the team. If result orientation is low, some external support is required to develop their result orientation. The average result orientation is 4.19 and the standard deviation calculated is 0.49 . Thus the level of result orientation of the employees is shown below in Table 17 .

Table 17. Levels of result orientation

\begin{tabular}{lcccc}
\hline Level of result orientation & Low & Medium & High & Total \\
\hline Number of responses & $18(20)$ & $55(62)$ & $16(18)$ & 89 \\
\hline
\end{tabular}

The Table 17 shows that out of 89 employees, $62 \%$ have medium level of result orientation. $18 \%$ of the employees have high level of result orientation. The relation between gender and level of result orientation is shown in Table 18. The average score of result orientation for males is 4.27 which is more than the overall average (4.19) and that of females is 4.09 which is less the average. To test whether there is any difference in levels of result orientation between the genders Table 18 is prepared.

Table 18. Gender and result orientation

\begin{tabular}{|c|c|c|c|c|}
\hline Gender & Low & Medium & High & Total \\
\hline Males & $6(12)$ & $32(67)$ & $10(21)$ & 48 \\
\hline Females & $12(29)$ & $23(56)$ & $6(15)$ & 41 \\
\hline Total & $18(20)$ & $55(62)$ & $16(18)$ & 89 \\
\hline
\end{tabular}


It is evident from the Table 18 that $21 \%$ of the male employees have higher level of result orientation which is greater than the overall percentage (18\%). The level of result orientation for female employees is $15 \%$ which is less than the overall percentage. Ho: Male employees have high level of result orientation than female employees. The $\chi^{2}$ value (3.94) is less than the critical value (5.99) at 5\% confidence level with 2 degrees of freedom. It is inferred that males show more result orientation than females in the work environment.

The relationship between experience and result orientation is analysed in Table 19. The average score of accountability for employees who are experienced more than 6 years and less than 2 years of experience is 4.25 and 4.27 respectively which is more than the average (4.19) whereas the average value of accountability for employees between 2 to 4 years and 4 to 6 years of experience is 4.07 and 4.12 which is less than the average (4.19). To observe whether there is any difference between the experience and result orientation level of employees Table 19 is prepared.

Table 19. Experience and result orientation

\begin{tabular}{|c|c|c|c|c|}
\hline Experience & Low & Medium & High & Total \\
\hline$<2$ years & $4(25)$ & $7(44)$ & $5(31)$ & 16 \\
\hline 2 to 4 years & $6(38)$ & $8(50)$ & $2(12)$ & 16 \\
\hline 4 to 6 years & $6(30)$ & $12(60)$ & $2(10)$ & 20 \\
\hline$>6$ years & $2(5)$ & $28(76)$ & 7 (19) & 37 \\
\hline Total & $18(20)$ & $55(62)$ & $16(18)$ & 89 \\
\hline
\end{tabular}

The Table 19 displays that $31 \%$ of employees experienced less than 2 years have high level of result orientation which is more than the overall percentage (18\%). The result orientation level is medium for $76 \%$ employees with more than 6 years of experience. Ho: Employees who are less experienced are more result oriented than the experienced employees. The $\chi^{2}$ value (12.43) is more than the critical value (12.59) at 5\% confidence level with 6 degrees of freedom. It is proved that employees who are less experienced are more result oriented than the experienced employees.

The relationship between education and result orientation is verified in Table 20. The average score of result orientation for employees who completed their higher secondary and diploma are 4.26 and 4.22 respectively which is more than the average of (4.19) whereas the average result orientation for employees qualified with baccalaureate and higher diploma are 4.03 and 4.18 which is less than the average (4.19). Table 20 verifies if there is any relationship between the education and result orientation of employees.

Table 20. Education and result orientation

\begin{tabular}{lcccc}
\hline Education & Lesult orientation & Medium & High & Total \\
\hline Higher Secondary & & & & \\
Diploma & $2(25)$ & $4(50)$ & $2(25)$ & 8 \\
Higher Diploma & $8(16)$ & $32(66)$ & $9(18)$ & 49 \\
Baccalaureate & $6(27)$ & $11(50)$ & $5(23)$ & 22 \\
Total & $2(20)$ & $8(80)$ & $0(0)$ & 10 \\
\hline
\end{tabular}

In the Table 20,25\% of employees qualified with higher secondary education have a high level of result orientation which is more than the overall percentage (18\%). The result orientation is medium for $80 \%$ of employees with baccalaureate and it is more than the overall percentage (62\%). $27 \%$ of employees who are higher diploma holders show low degree of result orientation which is more than overall percentage of $20 \%$. Ho: Employees who are less qualified focus more on result orientation than more educated employees. The $\chi^{2}$ value (4.60) is less than the critical value (12.59) at 5\% confidence level with 6 degrees of freedom. It is proved that bank employees who are less qualified focus more on result orientation than more educated employees. 


\subsection{Comparison of Team Climate Variables among Banks and Levels of Team Work Attributes}

Table 21. Comparison of team climate variables among banks

\begin{tabular}{|c|c|c|c|c|c|}
\hline Banks & Trust & Conflict Management & Commitment & Accountability & Result Orientation \\
\hline National Bank of Abu Dhabi & 4.56 & 4.08 & 4.48 & 4.26 & 4.43 \\
\hline Sohar Islamic Bank, Firq & 4.87 & 4.75 & 4.8 & 4.41 & 5 \\
\hline HSBC & 4.23 & 3.92 & 4 & 4 & 4.03 \\
\hline Bank Nizwa & 4.16 & 4.06 & 3.84 & 3.93 & 3.9 \\
\hline Ahli Bank & 4.83 & 4.76 & 4.28 & 4.76 & 4.6 \\
\hline Oman Arab Bank & 4.16 & 4.25 & 4.25 & 4.21 & 4.19 \\
\hline National Bank of Oman & 4.25 & 3.83 & 4 & 4.33 & 4.02 \\
\hline Alizz Islamic Bank & 4.06 & 4.25 & 4.1 & 4.33 & 4.29 \\
\hline Qatar International Bank & 4.66 & 4.4 & 4.46 & 4.16 & 4.11 \\
\hline Bank Sohar & 3.96 & 4.05 & 3.8 & 4.09 & 4.09 \\
\hline Bank Dhofar & 4.77 & 4.95 & 4.82 & 4.89 & 4.89 \\
\hline Bank Muscat, Industrial Branch & 4.11 & 3.76 & 4.06 & 3.94 & 4 \\
\hline Bank Muscat, Firq & 4 & 4.2 & 3.8 & 3.86 & 3.8 \\
\hline
\end{tabular}

Table 21 shows the overall team climate variables among all the banks used in this research. Trust average is high for Sohar Islamic Bank (4.87), whereas conflict management, commitment, accountability and result orientation averages are high in Bank Dhofar. In order to find whether there is any difference between these team climate variables among various banks anova test is adopted. It also helps to prove whether the means of these group variables are same or different. Ho: The means of the team climate variables are not related with banks.

Table 22. Anova test result

\begin{tabular}{lccccc}
\hline Source & df & SS & MS & F & P-value \\
\hline Treatments & 4 & 0.167 & 0.042 & 0.3412 & 0.8483 \\
Error & 60 & 7.324 & 0.122 & & \\
Total & 64 & 7.491 & & & \\
\hline
\end{tabular}

From the Table 22 it is found that the F- value is less than the p-value and hence the null hypothesis is accepted. Hence it is proved that the means of the group variables are not the same. Thus there is a difference in the means of these variables. It is inferred that trust factor is high in Sohar Islamic Bank and Bank Dhofar is better in conflict management, commitment, accountability and result orientation.

Table 23. Levels of team work variables

\begin{tabular}{lccc}
\hline Team work variables & Low & Medium & High \\
\hline Trust & $10(11)$ & $60(68)$ & $19(21)$ \\
Conflict Management & $15(17)$ & $56(63)$ & $18(20)$ \\
Commitment & $18(20)$ & $59(66)$ & $12(14)$ \\
Accountability & $18(20)$ & $59(66)$ & $12(14)$ \\
Result Orientation & $18(20)$ & $55(62)$ & $16(18)$ \\
Total & $79(18)$ & $289(65)$ & $77(17)$ \\
\hline
\end{tabular}


Among the team climate variables $21 \%$ of the respondents have high level of trust which is greater than the average (17\%). Conflict management is also high than the overall average. The high level of commitment and accountability (14\%) is less than the overall average (17\%). Ho: There is a significant difference in the team work variables. The $\chi^{2}$ value (6.21) is less than the critical value (15.50) at 5\% confidence level with 8 degrees of freedom. Hence the hypothesis is accepted. There is a significant difference among the team work variables and is thus concluded that trust, conflict management and result orientation are the high level attributes among team work variables in the banking sector.

\section{Findings of the Study}

1) Trust, conflict management and result orientation are the high level attributes among team work variables in the banking sector. Thus employees are able to work openly with one another. They are able to handle conflicts, and create good ideas. Employees are result oriented in a team that enables the team to stay focused and deliver more. It is also proved that commitment and accountability of employees in the banking sector in Nizwa is low.

2) The study proved that male employees show more trust level, conflict management, commitment, accountability and more result orientation than the female counterparts. Hence males contribute more and perform better in a team environment in the banking sector.

3) The results of this research proved that employees who are less experienced have a high level of trust, good in managing conflicts and are more result oriented than experienced employees. However the level of commitment of employees and their accountability are not influenced by experience.

4) From the analysis of team work attributes with education, it is tested and proved that employees who are less educated show more levels of trust, managing conflicts, commitment, accountability and focus on result than highly educated employees. This also reveals that the contribution of employees in team work environment in banking sector is more in the lower level than at the functional levels.

\section{Conclusion}

Team climate tends to be associated with a physical environment or a set of relationships which may or may not be interrelated. Team climate is very useful that it looks for characteristics of social and work situations that make an organization comfortable or productive. This paper presents a study to analyse the team climate variables. This study revealed that commitment and accountability of employees are low. Trust, conflict management and result orientation are contributing factors for team environment among the employees in the banking sector. The suggestions given through this study will help the banks to improve their team work climate. Banks should enrich the present knowledge and understanding on the building of an effective team. The results emphasize the significance of team attributes to ensure and nurture a positive team climate.

\section{Recommendations}

1) Employees are open and there are no conflict issues among them. Their commitment and accountability should be increased through proper motivation by the management. This will improve the performance of employees in the banking sector.

2) Females should be given more involvement in decision making and participation. A separate orientation for the female employees would help them to perform and contribute more in a team.

3) Experienced employees would set a role model for the less experienced staff. The experienced employees should contribute more in team environment.

4) An awareness and training program should be inducted for the employees to boost up the morale and improve their environment.

5) It is proved that commitment and accountability are low. Employees should be given awareness how to manage interdependent tasks. Awareness should be given to all the employees regarding team tasks. Also organization should clarify the roles and responsibilities to improve on accountability. At the same time results are achieved by the less experienced employees. Hence it is suggested that the top management should focus on these issues and unify the employees as a team.

6) The management should focus more on the team work culture to ensure employee satisfaction and productivity. Team work activities must be encouraged.

7) It is recommended that a government body should monitor performance of teams in banks and should award the best performing banks to increase motivation annually. 


\section{References}

Anderson, N. R., \& West, M. A. (1994). The team climate inventory: Manual and users'guide. Windsor U.K.: Assessment Services for Employment, NFER-Nelson.

Anderson, N. R., \& West, M. A. (1998). Measuring climate for work group innovation: Development and validation of the team climate inventory. Journal of Organizational Behavior, 19, 235-258. http://dx.doi.org/10.1002/(SICI)1099-1379(199805)19:3<235::AID-JOB837>3.0.CO;2-C

Gautam, T., Van Dick, R., \& Wagner, U. (2001). Organizational commitment in Nepalese setting. Asian Journal of Social Psychology, 4, 239-248. http://dx.doi.org/10.1111/1467-839X.00088

Gautam, T., Van Dick, R., Wagner, U., \& Upadhyay, N. (2005). Organizational citizenship behavior as an outcome of organizational commitment in Nepalese context. Asian Journal of Social Psychology, 8, 305-314. http://dx.doi.org/10.1111/j.1467-839X.2005.00172.x

Robert, L., \& Pamela, L. (2002). A confirmatory factor-analytic and psychometric examination of the team climate inventory. Small Group Research, 33(2), 254-265. http://dx.doi.org/10.1177/104649640203300205

Yuan, L., Peng, G., \& Chaoying, T. (2008). An empirical study on the relationship between team climate for innovation and perceived innovativeness in R\&D teams. International Conference on Information Management, Innovation Management and Industrial Engineering, 1, 203-206.

\section{Copyrights}

Copyright for this article is retained by the author(s), with first publication rights granted to the journal.

This is an open-access article distributed under the terms and conditions of the Creative Commons Attribution license (http://creativecommons.org/licenses/by/3.0/). 